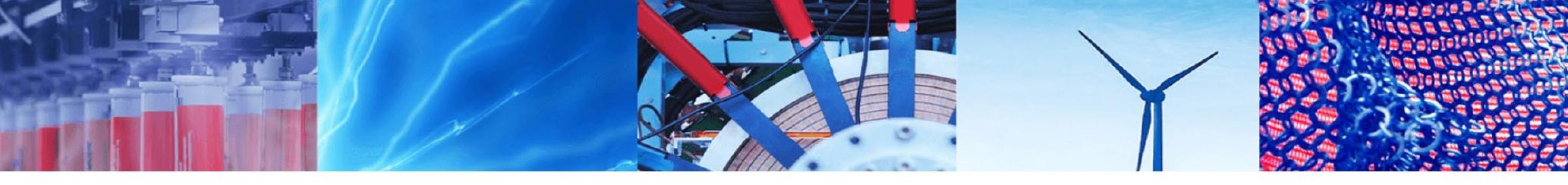

Research Article

\title{
Silver-zinc oxide nanocomposite antiseptic from the extract of Bidens pilosa
}

\author{
Hilda Dinah Kyomuhimbo ${ }^{1}$ - Immaculate Nyambura Michira ${ }^{1} \cdot$ Francis B. Mwaura ${ }^{2} \cdot$ Solomon Derese $^{1}$. \\ Usisipho Feleni ${ }^{3} \cdot$ Emmanuel I. Iwuoha $^{3}$
}

(c) Springer Nature Switzerland AG 2019

\begin{abstract}
Silver nanoparticles (Ag-NPs), zinc oxide (ZnO-NPs) and zinc oxide-silver (ZnO-Ag-NPs) were biosynthesized based on the rich matrix of alkaloids, flavones, tannins capping/stabilizing agents present in Bidens pilosa extract. Different plant parts-root, leaf and seed ware used to prepare the plant extract for synthesis. Also, zinc and silver nitrate salts were used as precursor materials. The surface plasmon peaks (SPR) based on the UV-Vis results for the Ag-NPs, ZnO-NPs were located between 408-411 and 365-450 nm respectively. The SPR peaks for the Ag-ZnO-NPs occurred at 300-450 nm indicating both blue and red shifts. The Ag-ZnO-NPs SPR shifts were associated with possible nanoparticle size reduction and change in dielectric constant of the synthesis medium. Raman measurement peaks at 356, 484, 1350, 1578, $2435 \mathrm{~cm}^{-1}$ associated with $\mathrm{OH},-\mathrm{C}==\mathrm{C}-,-\mathrm{C}-\mathrm{O}, \mathrm{S}=\mathrm{O},=\mathrm{C}-\mathrm{H}$ moieties indicated successful capping. Nanoparticle yield was temperature dependent and optimal yield could not be tied to a particular plant part as source of extract. Tunneling electron microscope results showed Ag-NPs and ZnO-NPs were globular/spherical with a diameter range of 2-20 nm. Interestingly, ZnO-NPs TEM displayed isolated miniaturized globular nanoparticles $(<2 \mathrm{~nm})$ which then joined up to form a large donut shaped structure indicating different formation mechanisms for the nanoparticles. XRD results showed the Ag-NPs, ZnO-NPs and the Ag-ZnO-NPs particles were crystalline in nature. The high signal/noise in XRD originated from possible crystalline biomaterials in the extracts. Energy dispersive spectroscopy (EDS) elemental composition results confirmed successful formation of the nanoparticles. Anti-Microbial activity of the synthesized Ag-NPs, ZnO-NPs and ZnO-Ag-NPs were studied against gram negative bacteria Escherichia coli (E. coli), gram positive bacteria Staphylococcus aureus and fungus Candida albicans. Different ZnO: Ag-NPs nanocomposite ratios were used to test for antimicrobial activity. Optimal antimicrobial activity was attained at Ag-NPs:ZnO-NPs ratio of 4:1 which also displayed the least minimum inhibition concentration (MIC) and therefore was used as the active ingredient in formulating a hand sanitizing antiseptic. The formulated antiseptic exhibited good antimicrobial activity.
\end{abstract}

Keywords Silver nanoparticles · Zinc oxide nanoparticles · Zinc oxide-silver nanoparticles $\cdot$ Antimicrobial activity $\cdot$ Hand sanitizing antiseptic

Hilda Dinah Kyomuhimbo and Immaculate Nyambura Michira have contributed equally to this manuscript.

$\square$ Hilda Dinah Kyomuhimbo, hildadinah@gmail.com | ${ }^{1}$ Department of Chemistry, University of Nairobi, Nairobi, Kenya. ${ }^{2}$ Department of Microbiology, University of Nairobi, Nairobi, Kenya. ${ }^{3}$ Sensor Lab, Department of Chemistry, University of Western Cape, Cape Town, South Africa.

SN Applied Sciences (2019) 1:681 | https://doi.org/10.1007/s42452-019-0722-y

Received: 23 February 2019 / Accepted: 4 June 2019 / Published online: 8 June 2019 


\section{Introduction}

The rampant spread of infectious diseases globally cannot be overlooked [1, 2]. Antimicrobial drugs, disinfectants and antiseptics have been introduced to counter the cause and spread of these infectious diseases, however, the resistance of microbial strains against the antimicrobial drugs is increasing at an alarming rate due to inappropriate use of antimicrobial drugs [3-7]. Therefore there is a need in the use of an agent that does not generate resistance, presents good antimicrobial property and without cytotoxic effects on humans and other species [8-10]. Nanosized antimicrobial agents have gained popularity due to their high stability and enhanced antimicrobial activities $[9,11]$. The versatility of nanoparticles in rendering themselves to many applications is currently being explored. Top in the list are silver nanoparticles (Ag-NPs) and zinc oxide nanoparticles (ZnO-NPs) which find applications in medicine, sensors, renewable energies, cosmetology, environmental remediation, bio-therapeutic devices, clothing, surface disinfection and antimicrobial applications [12-23]. This could be attributed to their small size and large surface arear to volume ratio which gives them improved physical, biological and chemical properties as compared to their large scale counter parts [24, 25]. Ag-NPs and $\mathrm{ZnO}$ NPs have been proved to have effective antimicrobial activity at very low concentrations even to resistant strains of microbes $[26,27]$. This is because they destroy many biological pathways in a cell and it would necessitate the microorganism to go through many concurrent transmutations so as to develop resistance $[7,28]$. More so they need very short contact time to cause a long lasting cell growth inhibition [29,30]. Of recent, the Ag/ $\mathrm{ZnO}$ nanocomposite has been found to show enhanced antimicrobial activity against the common microbes as compared to the individual nanoparticles [31]. This is because the properties of the hybrid are not just the sum of the individual advantages of both nanoparticles but are derived from their synergic effect which creates a new class of hybrid-nanomaterials [11]. Also the synergic effect of $\mathrm{Ag}$ and $\mathrm{ZnO}$ is beneficial for mass production of Reactive Oxygen Species such as $\mathrm{H}_{2} \mathrm{O}_{2}$, hence increased antimicrobial activity of nanocomposite [32, 33]. Several nanoparticle synthesis methodologies have been employed including chemical methods [34], electrochemical methods [35], gamma radiation methods [36], photochemical [37] as well as laser ablation techniques [38]. A major impeding barrier as to employment of most of these conventional methods in nano-production is that they are cost prohibitive and also that some make use of harmful solvents and synthetic reactants which are environmental non-friendly [39-47].

Green nanotechnology on the other hand makes use of environmentally benign materials which are readily available at minimal or no cost $[2,21]$. The nanoparticles produced by this method are usually stable, hydrophilic and have very small diameter [48-51]. In addition, plant extract precursors, have an extensive variety of active ingredients which aid in the reducing and stabilizing process and also act as templates for the modulation of nanostructure formation. The biosynthesizing precursors are not only safe to handle but the process easily renders itself to scaling up without use of energy, high temperatures or toxic reagents thereby giving an environmentally friendly alternative to physical and chemical syntheses [2, 19, 45, 52-54].

Several plant extracts have been used as stabilizers, reducing and templating or structure directing agents for silver and zinc oxide nanoparticles synthesis. Camellia sinesis [55], Hibiscus rosa-sinensis [56], Rumex hymenosepalus [57], Cissus quadrangularis [58], Olea rupea [59], Octinum sanctum [46], Ocimun tenuiflorum $[51,60]$ and Panicum virgatum [61] amongst others have been used. The presence of many polyphenols $[2,13,34,62]$ in the extracts not only allow them to exhibit high antioxidant activity but to act as strong reducing agents owing to the presence of many hydroxyl $(\mathrm{OH})$ groups in their structural composition [46].

Bidens pilosa contains several bio-molecules of the polyphenols type (Scheme 1) [55-61, 63-69]. It is believed that these biomolecules are the stabilizing, reducing and nanostructurizing media that guide the formation of the various nanoparticles.

So far no work on nanotechnology has been carried out using Bidens pilosa. In this work, silver, zinc oxide and silver-zinc oxide nanoparticles stabilized/capped by Bidens pilosa ligands were synthesized. The antimicrobial properties of Ag-NPs-ZnO-NPs hybrid nanoparticles and possible application in formulating a hand antiseptic are discussed. The efficacy of the formulated antiseptic against E. coli, S. aureus and C. albicans is explored.

\section{Materials and methods}

Bidens pilosa plants were obtained from University of Nairobi compound. Silver nitrate, Zinc nitrate and guar gum were purchased from Sigma Aldrich. Microorganisms of $E$. coli, S. aureus, and C. albicans were obtained from Department of Microbiology, University of Nairobi. Chloramphenicol and Fluconazole were purchased from a nearby pharmacy around the University. Pure glycerin, chantia fragrance and a-tocopherol were purchased from a nearby pharmacy around the University of Nairobi. 
<smiles>O=C(O)/C=C/C(=O)O</smiles>

2-Butanedioic acid<smiles>COc1cc(/C=C/C(=O)O)ccc1O</smiles>

3-(4-Hydroxy-3-methoxyphenyl)-2-propenoic acid<smiles>O=C(O)c1cc(O)c(O)c(O)c1</smiles>

3,4,5-Trihydroxybenzoic acid<smiles>O=c1c(O)c(-c2ccc(O)c(O)c2)oc2cc(O)cc(O)c12</smiles>

2(3,4-Dihydroxyphenyl)-3,5,7-

trihydroxy-4H-1-benzopyran-4-one<smiles>O=C1CC(c2ccc(O)c(O)c2)Oc2c1ccc(O)c2O</smiles>

2-(3,4-Dihydroxylphenyl)-2,3-dihydro-7,8-dihydroxy-4H-1-benzopyran-4-one

Scheme 1 Structures of some of the compounds found in Bidens pilosa

\subsection{Sample collection and leaf extract preparation}

The plant (Bidens pilosa) was collected from Nairobi County. The seeds, leaves and roots were plucked separately from the plant and washed with distilled water, dried under shed and ground to powder. $2 \mathrm{~g}$ of each of the seed, leaf and root powders were boiled in $250 \mathrm{~mL}$ of distilled water at $90{ }^{\circ} \mathrm{C}$ for $10 \mathrm{~min}$, allowed to cool under nitrogen gas and filtered using a filter paper. The residues were discarded. The filtrates were centrifuged at $14,500 \mathrm{rpm}$ for $10 \mathrm{~min}$ to obtain the seed, leaf and root extracts. The above procedure was repeated at temperatures of 65,45 and $25{ }^{\circ} \mathrm{C}$ to demonstrate the effect of varying extraction temperature on the spectroscopic properties and yield of the silver and zinc oxide nanoparticles.

\subsection{Synthesis of Ag-NPs, ZnO-NPs and ZnO-Ag-NPs}

$20 \mathrm{~mL}$ of the seed extract obtained at $90^{\circ} \mathrm{C}$ were transferred to a beaker into which $80 \mathrm{~mL}$ of $1 \mathrm{mM}$ silver nitrate solution was added drop wisely. The mixture was allowed to stand for $2 \mathrm{~h}$ under nitrogen gas blanket. Exactly $1 \mathrm{~mL}$ of this mixture was transferred to a cuvette for UV-Vis analysis. The rest of the mixture was centrifuged at $14,500 \mathrm{rpm}$ for $10 \mathrm{~min}$. The supernatant obtained after centrifugation was transferred to the oven where it was dried at $60^{\circ} \mathrm{C}$ for $8 \mathrm{~h}$. The nanoparticles were removed and transferred to a 
closed container and kept for further analysis. The above procedure was carried out for seed, leaf and root extracts obtained at $90^{\circ} \mathrm{C}, 65^{\circ} \mathrm{C}, 45^{\circ} \mathrm{C}$ and $25^{\circ} \mathrm{C}$.

For synthesis of $\mathrm{ZnO}-\mathrm{NPs}$, the above procedure was repeated with $80 \mathrm{~mL}$ of $1 \mathrm{mM}$ zinc nitrate solution. For the $\mathrm{ZnO}-\mathrm{Ag}-\mathrm{NPs}$, the above procedure was repeated with $80 \mathrm{~mL}$ of varying volumes of silver nitrate and zinc nitrate solutions to obtain various compositions of $\mathrm{AgNO}_{3} /$ $\mathrm{Zn}\left(\mathrm{NO}_{3}\right)_{2}$ solutions. The loading of Ag was based on volume to volume ratios of silver nitrate solution to zinc nitrate solution. $\mathrm{AgNO}_{3}: \mathrm{Zn}\left(\mathrm{NO}_{3}\right)_{2}$ volume ratios used were between 0:1 that is; $0.2\left(16 \mathrm{~mL} \mathrm{AgNO}{ }_{3}, 64 \mathrm{~mL} \mathrm{Zn}\left(\mathrm{NO}_{3}\right)_{2}\right)$, $0.4\left(32 \mathrm{~mL} \mathrm{AgNO}{ }_{3}, 48 \mathrm{~mL} \mathrm{Zn}\left(\mathrm{NO}_{3}\right)_{2}\right), 0.5\left(40 \mathrm{~mL} \mathrm{AgNO}{ }_{3}\right.$, $\left.40 \mathrm{~mL} \mathrm{Zn}\left(\mathrm{NO}_{3}\right)_{2}\right), 0.6\left(48 \mathrm{~mL} \mathrm{AgNO}{ }_{3}, 32 \mathrm{~mL} \mathrm{Zn}\left(\mathrm{NO}_{3}\right)_{2}\right)$ and $0.8\left(64 \mathrm{~mL} \mathrm{AgNO}{ }_{3}, 16 \mathrm{~mL} \mathrm{Zn}\left(\mathrm{NO}_{3}\right)_{2}\right)$.

\subsection{Characterization of Ag-NPs, ZnO-NPs and ZnO- Ag-NPs}

The Surface Plasmon Resonance (SPR) properties and spectral analysis of the nanoparticles were analyzed using UV-visible spectrometer [UV-1700 pharmaspec UV-Vis spectrophotometer (shimadzu)]. The extracts, AgNPs, ZnO-NPs and ZnO-Ag-NPs were subjected to Fourier Transform Infrared (FTIR-JASCO 4100) to determine capping of biomolecule on the surface of the nanoparticles. The Ag-NPs, ZnO-NPs and ZnO-Ag-NPs were subjected to Raman spectroscopy (Renishaw RM1000) to further identify the functional groups responsible for their capping and stabilization. The Ag-NPs, ZnO-NPs and $\mathrm{ZnO}-\mathrm{Ag}-\mathrm{NPs}$ powders were characterized by X-ray Diffraction (SIEMENS D5005 Diffractometer) and Transmission Electron Microscopy (Philips Technai-F12) and Scanning Electron Microscopy (Hitachi S-3000N).

\subsection{Antimicrobial activity of Ag-NPs}

The antimicrobial activity of Ag-NPs, ZnO-NPs and ZnO-Ag-NPs was evaluated against gram positive Staphylococcus aureus, gram negative Escherichia coli and fungus Candida albicans. Microorganisms of E. coli, S. aureus, and C. albicans were obtained from Department of Microbiology, University of Nairobi. These microorganisms were chosen as representative strains of gram positive and gram negative bacteria owing to their unique shell envelop structure. They also are not only easy to culture in the laboratory but also live on the human skin surface meaning a successful study would be a step towards human health problems [3].

Fresh overnight inoculums $(50 \mu \mathrm{L})$ of each culture were spread on to agar plates. Wells of $6 \mathrm{~mm}$ diameter were made in the agar pates using a sterile coke borer. $5 \mathrm{~mL}$ of Ag-NPs solution of concentration $100 \mu \mathrm{g} / \mathrm{mL}$ was prepared by dispersing Ag-NPs in distilled water. $45 \mu \mathrm{L}$, of Ag-NPs solution was poured into the wells. The $E$. coli and $S$. aureus plates were incubated at $37^{\circ} \mathrm{C}$ for $24 \mathrm{~h}$. The plates with $C$. albicans were left to stand at room temperature for $48 \mathrm{~h}$. The diameters of zones of inhibitions were recorded. The above procedure was repeated for $\mathrm{ZnO}-\mathrm{NPs}$ and $\mathrm{ZnO}-\mathrm{Ag}-\mathrm{NPs}$.

\subsection{Determination of minimum inhibitory concentration}

Exactly $13 \mathrm{~g}$ of nutrient broth was weighed in a beaker into which $100 \mathrm{~mL}$ of distilled water was added while stirring. The medium was then transferred to $1 \mathrm{~L}$ medium sterilizing bottle which was brought to a boil and then allowed to cool. The cooled medium was then poured into $15 \mathrm{~mL}$ tubes each tube receiving $9 \mathrm{~mL}$. This was followed by autoclaving the medium containing tubes at a pressure of 15 Psi for $15 \mathrm{~min}$ in order to kill any microorganisms present.

To make an Ag-NPs/medium stock solution, one autoclaved medium containing tube was selected. Into this tube $1 \mathrm{~mL}$ Ag-NPs solution was transferred using a micropipette and the mixture thoroughly shaken to ensure formation of a uniform mixture. This was the $10 \mu \mathrm{g} / \mathrm{mL}$ Ag-NPs concentration. From this stock solution, a $1 \mu \mathrm{g} /$ $\mathrm{mL}$ Ag-NPs concentration was made by drawing out an aliquot of $1 \mathrm{~mL}$ again from the stock solution and adding it to a new autoclaved medium containing tube followed by thorough shaking. By micro pipetting $1 \mathrm{~mL}$ of the $1 \mu \mathrm{g} /$ $\mathrm{mL}$ Ag-NPs solution and placing it in another autoclaved medium, a $0.1 \mu \mathrm{g} / \mathrm{mL} \mathrm{Ag-NP}$ concentration was made.

In order to test the effect of the different concentrations of the nanoparticles (10, 1, $0.1 \mu \mathrm{g} / \mathrm{mL}$ Ag-NPs) E. coli media was scooped and transferred to each of the three tubes and the extent of inhibition determined. The above procedure was repeated for S. aureus and C. albicans. Similar procedure was followed for ZnO-NPs and the Ag-NPs/ ZnO-NPs nanohybrid.

\subsection{Formation of hand sanitizing antiseptic}

$77.1 \mathrm{~g}$ of deionized water was placed into a beaker followed by $0.7 \mathrm{~g}$ of guar gum (gelling agent). The solution was heated to a temperature of $50{ }^{\circ} \mathrm{C}$ while stirring at $1000 \mathrm{rpm}$ for $30 \mathrm{~min}$. The solution was then allowed to cool to room temperature and $2 \mathrm{~g}$ of a-tocopherol (emollient) and $0.1 \mathrm{~g}$ of $\mathrm{ZnO}-\mathrm{Ag}-\mathrm{NPs}$ (0.8Ag-NPs/0.2 ZnO-NPsactive ingredient) was added while stirring at $1000 \mathrm{rpm}$. Lastly $7 \mathrm{~g}$ of pure glycerin (humectant) followed by $0.2 \mathrm{~g}$ of fragrance (Chantia) were added to the mixture. The mixture was stirred for more $30 \mathrm{~min}$ at $1000 \mathrm{rpm}$ at room temperature. The antiseptic/hand sanitizer was then allowed to stand for $2 \mathrm{~h}$ and then tested for antimicrobial activity. 


\section{Results and discussion}

The formation of the Ag-NPs, ZnO-NPs and Ag-NPs/ZnONPs nanohybrids were marked by an onset of colour changes upon mixing the reactants. The colour changed from a bright yellow to brown and then to dark brown after 5 min with precipitation signaling formation of ZnO-NPs. For silver nanoparticles, the final colour turned into a cloudy dark grey after $5 \mathrm{~min}$. Interestingly the final colour of the $\mathrm{ZnO}-\mathrm{Ag}-\mathrm{NPs}$ depending on the ratio lay between yellow and grey with the majority having a tinge of brown colour. In fact the colour of the $\mathrm{ZnO}-\mathrm{Ag}$ NPs was an intermediate of the colour of $\mathrm{ZnO}$-NP solution and Ag-NP solution that is a brown colour (Fig. 1)

A UV-Vis scan of the formed Ag-NPs gave rise to the surface pasmon band in almost the same wavelength (408-411 nm) for each extract type indicating each of the selected plant parts yielded adequate polyphenolic materials for the nanostructurizing work Fig. 2a. This surface plasmon band results from the interaction between the conduction electrons and the striking radiation. A similar
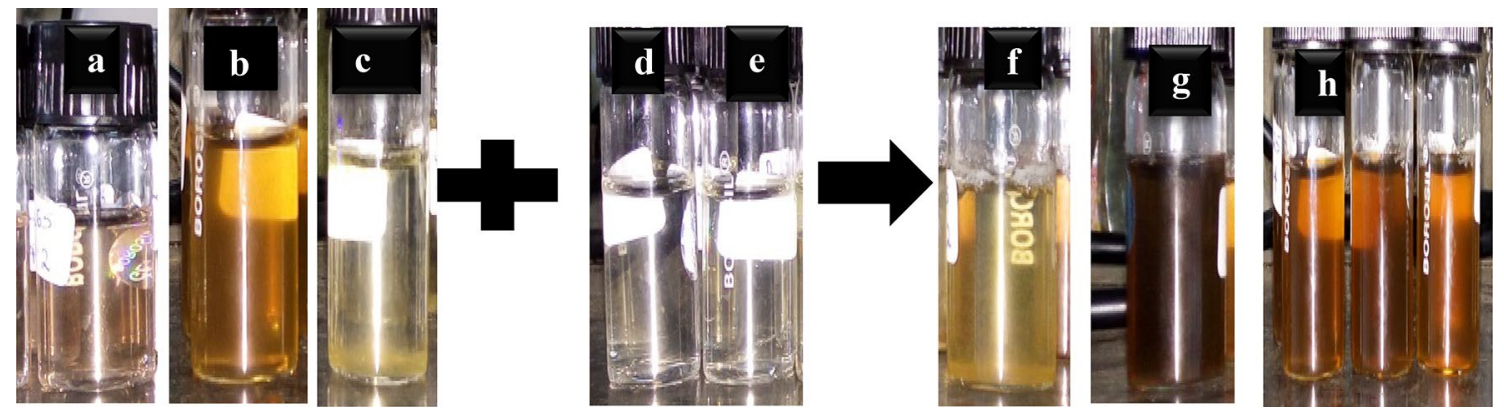

Fig. 1 a Seed extract, b leaf extract, $\mathbf{c}$ root extract, $\mathbf{d}$ silver nitrate, e zinc nitrate, $\mathbf{f}$ solution containing ZnO-NPs, $\mathbf{g}$ solution containing Ag$\mathrm{NPs}$ and $\mathbf{h}$ solutions containing $\mathrm{ZnO}-\mathrm{Ag}-\mathrm{NPs}$
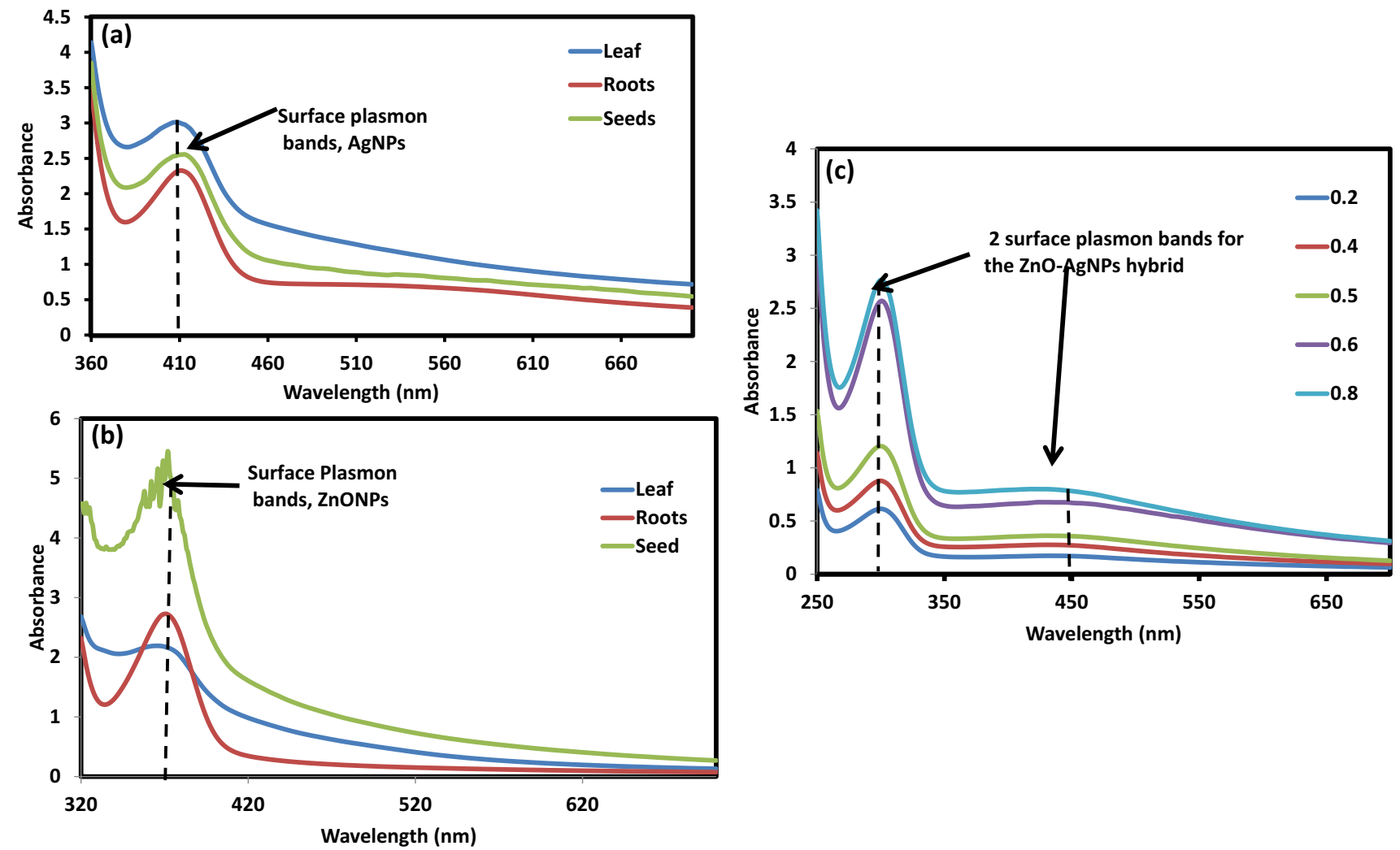

Fig. 2 UV-Vis spectra for Ag-NPs (a), ZnO-NPs (b) and Ag-NPs-ZnO-NPs (c) showing the surface plasmon band(s) 
observation was made for the $\mathrm{ZnO}$-NPs nanocomposites whose plasmon band ranges were $365-372 \mathrm{~nm}$ Fig. 2b. A double band at around 300 and $450 \mathrm{~nm}$ was observed for the $\mathrm{ZnO}-\mathrm{Ag}-\mathrm{NPs}$ (Fig. 2c) nanoparticles a clear indication, of the successful formation of the hybrid. In the hybrid the band corresponding to ZnO-NPs showed a significant blue shift while that corresponding to Ag-NPs showed a significant red shift. This could be due to electromagnetic coupling between the $\mathrm{Ag}$ and $\mathrm{ZnO}$ which leads to inphase interactions between adjacent colloidal nanoparticles hence the blue and red shift in ZnO-NPs and AgNPs respectively. The red shift of the Ag-NPs band could be attributed to increased charge magnitude on mixing the two and possible different interaction with synthesis medium [70-72]. Elsewhere blue shift has been associated with nanoparticle size reduction as well as change in the synthesizing media dielectic constant [73].

Variation of the synthesis temperature indicated nanoparticle yield increased with increase in temperature. This was the general observation observed across all the nanoparticle types whether Ag-NPs, ZnO-NPs or ZnO-Ag-NPs irrespective of the part of plant used as source of the stabilizing agents. The masses of the product nanoparticles were calculated using Eq. 1

$\%$ yield of $A g N P S=\frac{\text { Mass of } \mathrm{Ag}-\mathrm{NPs}}{\text { Mass of } \mathrm{Ag} \text { ion in solution }} \times 100$

\subsection{Effect of temperature on the yield}

Figure 3a-c shows an upward yield trend for all the nanoparticles with temperature although the actual plant part that led to maximum yeild was erratic. For all temperatures $>80^{\circ} \mathrm{C}$, the nanoparticle yield irrespective of the source of the stabilizing agents was well above $80 \%$.

An increase in nanoparticle yield with temperature could mean the mechanism for nanoparticle formation is in line with arrhenius theory which highlights that reaction rates rise with temperature. An increase in temperature increases the kinetic energy of the precursor materials hence enhancing the rate of collision of the reacting spieces with a higher part of collisions exceeding the threshold of activation energy. This in turn increases the amount of nanoparticles produced as the temperature of the extract increases $[74,75]$. For all the cases it was found maximum nanoparticle yield was obtained at a maximal temperature of $90^{\circ} \mathrm{C}$. However, each part of the plant gave different yields for the various nanoparticles, that is, the seed extract gave the highest yield for ZnONPs; the leaf extract gave the highest yield for AgNPs while the root extract gave the highest yield for the $\mathrm{ZnO}-$ AgNPs.
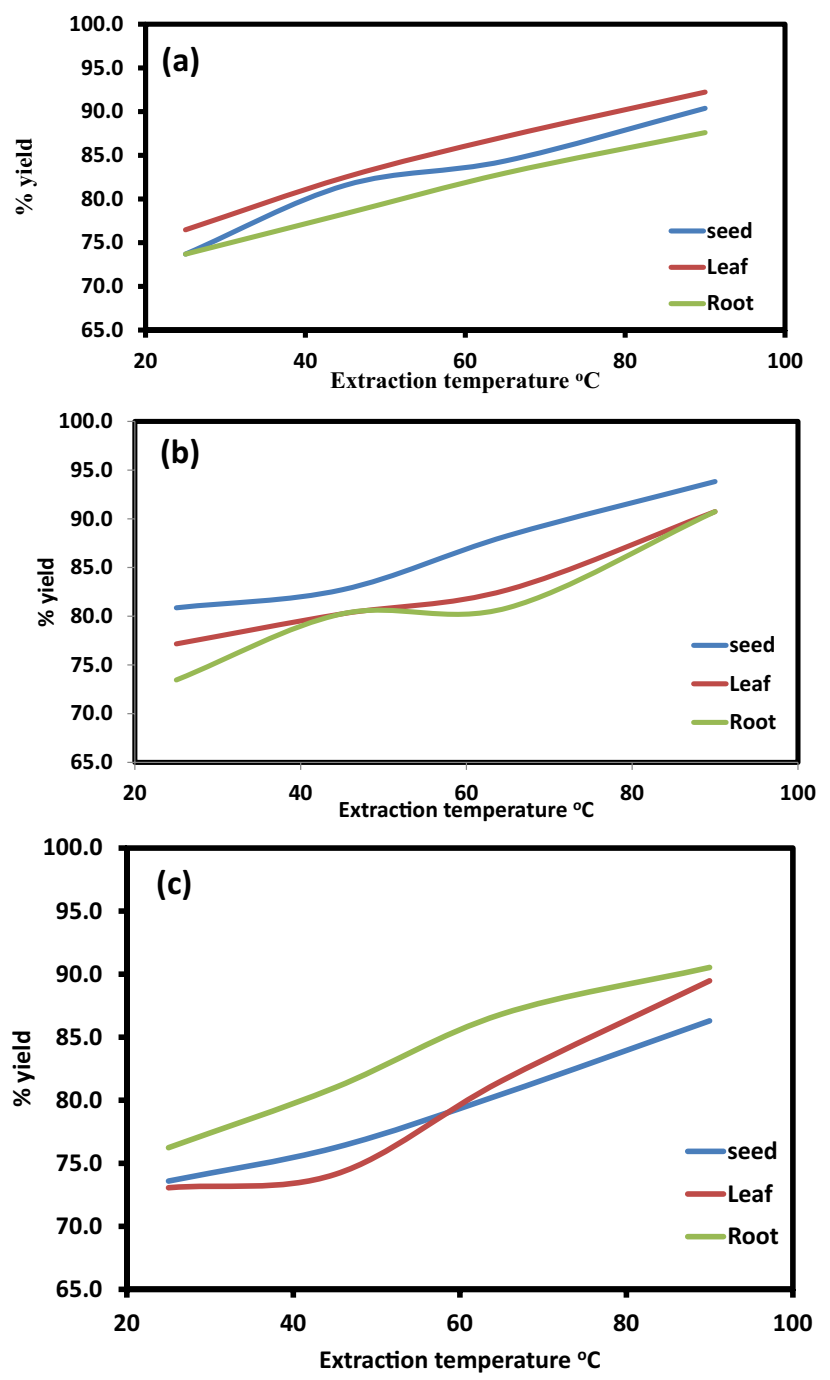

Fig. 3 Showing yield dependence on extraction temperature for Ag-NPs (a), ZnO-NPs (b) and Ag-NPs-ZnO-NPs (c)

Since Ag-NPs and ZnO-NPs have been known to exhibit antimicrobial properties, the aim of the research was to produce $\mathrm{ZnO}-\mathrm{Ag}$-NPs nanohybrids and test for their antiseptic effect. Through experimentation by varying the composition of the Ag-NPs in the hybrid, it was established that an Ag-NPs:ZnO-NPs ratio of 0.8:0.2 (4:1) gave rise to highest absorbance-a typical result is presented in Fig. 4 . Further analysis of the nano-products was based on samples produced at optimal conditions.

Further characterization was based on results obtained at these optimal conditions.

\subsection{Raman and FTIR results}

The functional groups mainly $\mathrm{OH},-\mathrm{C}=\mathrm{C}-, \mathrm{C}-\mathrm{O}, \mathrm{S}=\mathrm{O},=\mathrm{C}-\mathrm{H}$ bending and aromatic $\mathrm{C}-\mathrm{H}$ bending derived from heterocyclic compounds or alkanols e.g. alkaloid, or flavones and 


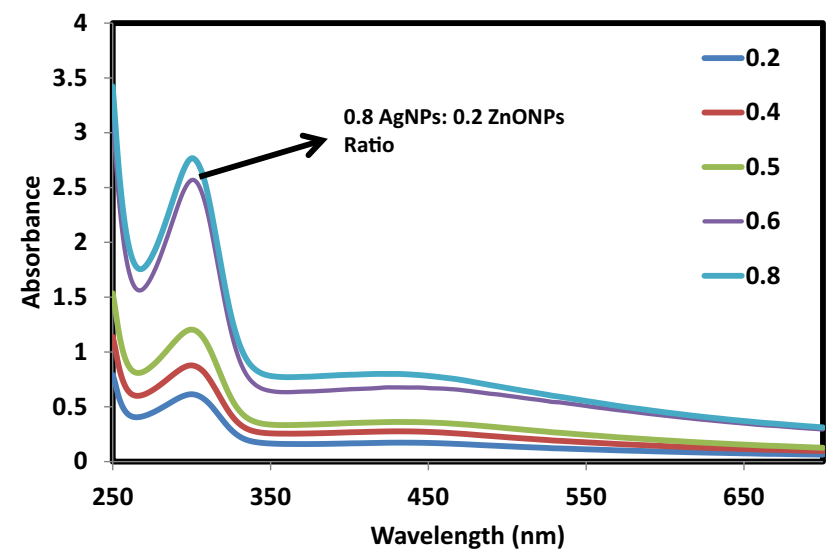

Fig. 4 UV-Vis spectra of Ag-NPs-ZnO-NPs from root extract of Bidens pilosa at varying composition of Ag-NPs tannins are present in Bidens pilosa extracts and are the capping ligands of the nanoparticles. This shows that the compounds from the extracts cap and stabilize the nanoparticles during the synthesis process.

Figure $5 \mathrm{a}-\mathrm{c}$ compares and contrasts the Raman spectra of the Ag-NPs, ZnO-NPs and the Ag-NPs-ZnO-NPs nanoparticles.

There is a general appearance of some broad Raman bands indicating some presence of some degree of amorphousness across the three spectra (Fig. $5 a-c$ ). Broad bands are as a result of distortions of interatomic bond angles and the consequent overcrowding due to the presence of many such distortions [76]. Interestingly, the occurrence of Raman shifts as low as $158 \mathrm{~cm}^{-1}$ is indicative of Ag lattice vibrations indicative of some degree of crystallinity. Other bands for Ag-NPs that were obtained
Fig. 5 Raman spectra of the Ag-NPs (a), ZnO-NPs (b) and the nanohybrid Ag-NPs-ZnONPs (c) at a ratio of 0.8:0.2
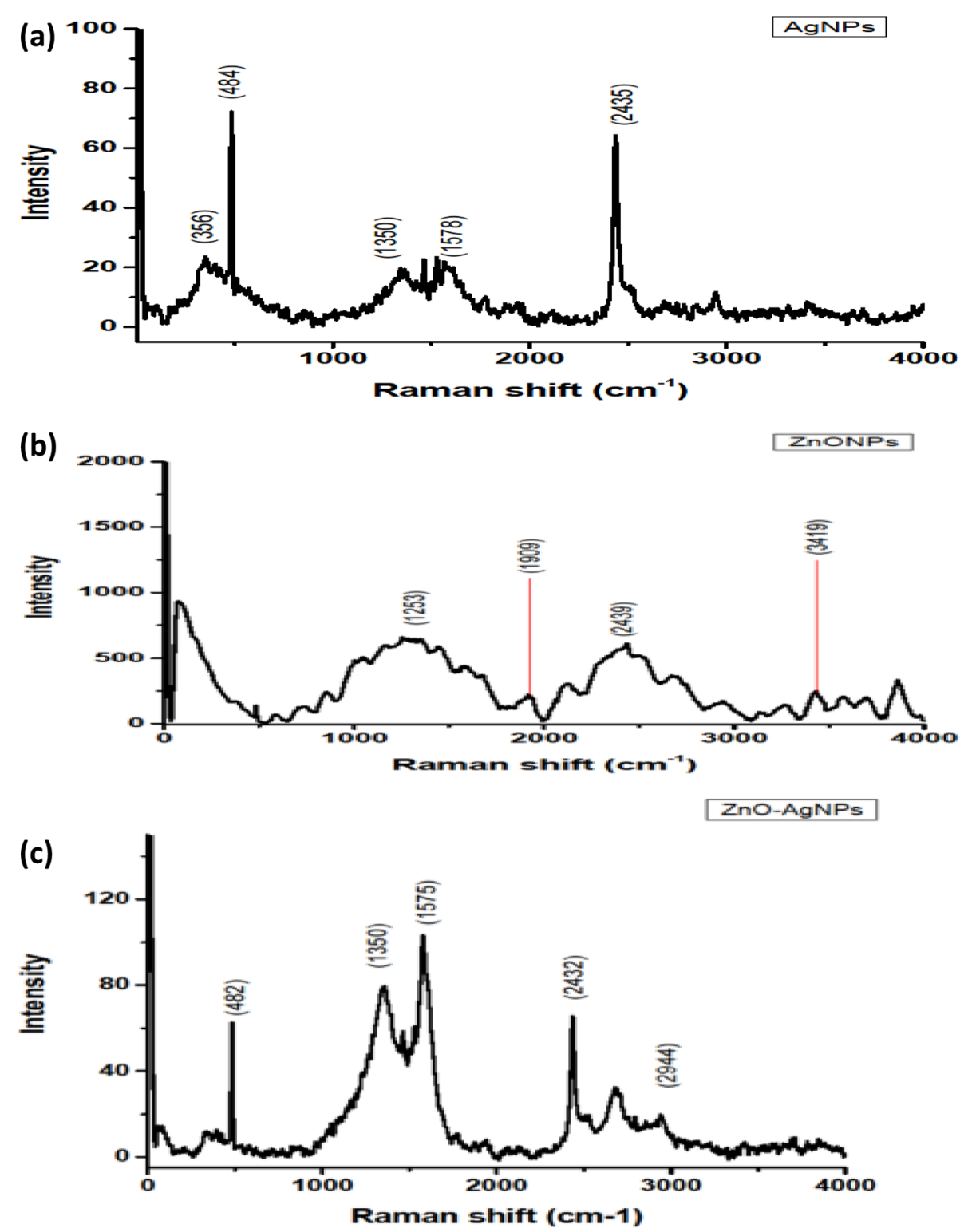

SN Applied Sciences 
include; $356 \mathrm{~cm}^{-1}$ corresponding to $\mathrm{C}-\mathrm{C}$ bending vibration of aliphatic chains, $484 \mathrm{~cm}^{-1}$ corresponding to $S-S$ bonds, $1350 \mathrm{~cm}^{-1}$ corresponding to carboxylate salt, $1578 \mathrm{~cm}^{-1}$ corresponding to aromatic ring and $2435 \mathrm{~cm}^{-1}$ corresponding to thiol group. The functional groups attached to the silver nanoparticles confirm that the leaf extract contains compounds that reduce the $\mathrm{Ag}+\mathrm{to}^{\mathrm{Ag}}$ and also stabilize the Ag-NPs formed. Similar functional groups were confirmed from the FTIR results (Table 1).

\subsection{TEM results}

Tunneling electron microscopy results show that the prepared nanoparticles exhibit diameters of between 2 and $20 \mathrm{~nm}$ (Fig. 6a-C). EDS results (Fig. 6d-f) of the Ag-NPs nanoparticles indicated presence of elemental silver at 3.2 and $2.9 \mathrm{keV}$ due to $\mathrm{Ag} \mathrm{L}$ line transitions while as those of $\mathrm{ZnO}$-NPs were observed 1, 8.6, $9.5 \mathrm{keV}$ corresponding to the $\mathrm{Zn} \mathrm{L}$ lines, $\mathrm{Zn} \mathrm{K}$ and $\mathrm{Zn} \mathrm{K}_{\beta}$ line respectively $[77,78]$. The appearance of peaks due to $\mathrm{P}, \mathrm{S}, \mathrm{O}, \mathrm{Na}$ was associated with plant extracts origin because these elements can be absorbed from soil, while as $\mathrm{Cu}$ is from the TEM grid. The Ag-NPs-ZnO-NPs nanohybrid clearly indicates the presence of both $\mathrm{Ag}$ and $\mathrm{Zn}$ nanoparticles a successful indication of the formation of the nanohybrid. Charging effects due to build-up of electrons in the sample is evident both in the TEM and in the SEM results, a characteristic of the presence of poor conducting, stabilizing organic moieties.

The Ag-NPs exhibited globular/spherical shape as compared to that of the ZnO-NPs. The latter exhibited miniature isolated globular nanoparticles $(<2 \mathrm{~nm})$ which then joined up to form larger globules (Fig. $6 \mathrm{~g}-\mathrm{i}$ ). Interestingly these giant globular aggregates joined up to form a large donut shaped structure with a hollow center. Looking at
Table 1 Values for IR bands for the extracts and nanoparticles obtained using FTIR

\begin{tabular}{|c|c|c|}
\hline Extract (wave number $/ \mathrm{cm}^{-1}$ ) & $\begin{array}{l}\text { Nanoparticles (wave number/ } \\
\mathrm{cm}^{-1} \text { ) }\end{array}$ & Functional group \\
\hline \multirow[t]{2}{*}{ Leaf extract } & AgNPs & \\
\hline & 3448 & Free O-H \\
\hline \multirow[t]{5}{*}{2772} & & O-H stretch for carboxylic acid \\
\hline & 1560 & Aromatic $\mathrm{C}=\mathrm{C}$ stretch \\
\hline & 1489 & $\mathrm{C}-\mathrm{H}$ bending alkane-methyl group \\
\hline & 1307 & $\mathrm{C}-\mathrm{O}$ stretching aromatic ester \\
\hline & 1298 & $\mathrm{~S}=\mathrm{O}$ stretching sulfone \\
\hline 1151 & 112 & $\mathrm{C}-\mathrm{O}$ stretch \\
\hline 912 & & $=\mathrm{C}-\mathrm{H}$ bending \\
\hline 728 & & Aromatic $\mathrm{C}-\mathrm{H}$ bending \\
\hline \multirow[t]{2}{*}{ Seed extract } & ZnONPs & \\
\hline & 3432 & Free O-H \\
\hline \multirow[t]{5}{*}{2772} & & O-H stretch for carboxylic acid \\
\hline & 1559 & $\mathrm{C}=\mathrm{C}$ stretch \\
\hline & 1489 & $\mathrm{C}-\mathrm{H}$ bending alkane-methyl group \\
\hline & 1307 & $\mathrm{C}-\mathrm{O}$ stretching aromatic ester \\
\hline & 1298 & $\mathrm{~S}=\mathrm{O}$ stretching sulfone \\
\hline 1151 & & $\mathrm{C}-\mathrm{O}$ stretch \\
\hline 912 & & $=\mathrm{C}-\mathrm{H}$ bending \\
\hline 728 & & Aromatic $\mathrm{C}-\mathrm{H}$ bending \\
\hline 603 & & $\mathrm{C}-\mathrm{I}, \mathrm{C}-\mathrm{Br}$ stretching for halo compound \\
\hline \multirow[t]{2}{*}{ Root extract } & $\mathrm{ZnO}-\mathrm{AgNPs}$ & \\
\hline & 3432 & Free O-H \\
\hline \multirow[t]{5}{*}{2928} & & O-H stretch for carboxylic acid \\
\hline & 1564 & $\mathrm{C}=\mathrm{C}$ stretch \\
\hline & 1490 & $\mathrm{C}-\mathrm{H}$ bending alkane-methyl group \\
\hline & 1307 & $\mathrm{C}-\mathrm{O}$ stretching aromatic ester \\
\hline & 1292 & $\mathrm{~S}=\mathrm{O}$ stretching sulfone \\
\hline 1151 & & $\mathrm{C}-\mathrm{O}$ stretching \\
\hline 912 & & $=\mathrm{C}-\mathrm{H}$ bending \\
\hline 728 & & Aromatic $\mathrm{C}-\mathrm{H}$ bending \\
\hline
\end{tabular}



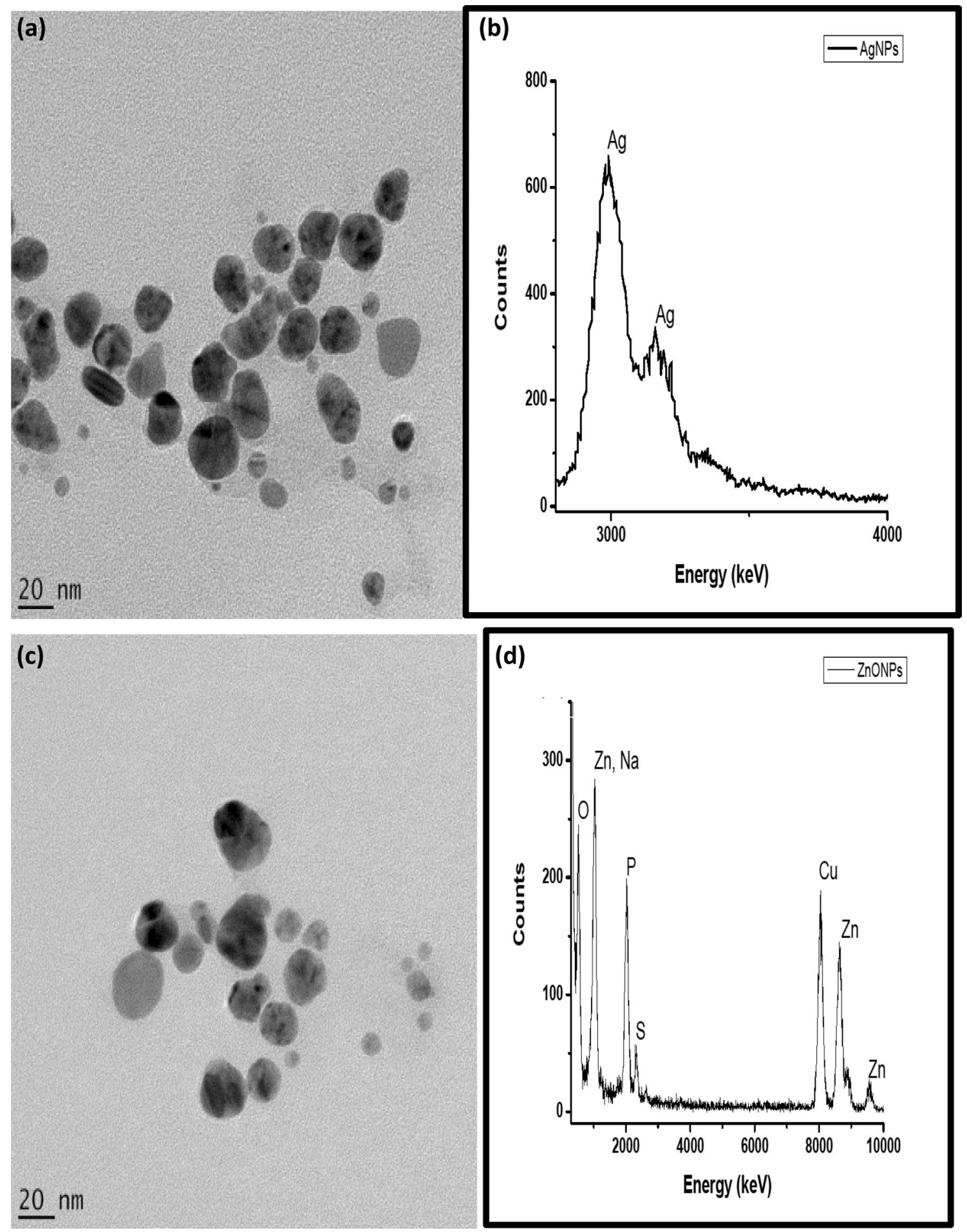

Fig. 6 Tunneling electron micrographs for Ag-NPs (a), ZnO-NPs (c) and Ag-NPs-ZnO-NPs hybrid (e). Energy dispersive spectra for Ag-NPs (b), ZnO-NPs (d) and Ag-NPs-ZnO-NPs (f). Scanning electron micrographs for Ag-NPs (g), ZnO-NPs (h) and Ag-NPs-ZnO-NPs (i)

the rear of the donut crystal, co-joint segments boundaries are visible probably indicating stepwise formation of this donut structure. Similar observations were made by Buthysusnatao et al. [79] who concluded that the crystal growth is bidirectional while working on $\mathrm{Mg}-\mathrm{OH}$ crystals. It appears the magnitude of the charge on a particle influences the resultant morphology. However, this donut morphology is not distinct in the Ag-NPs-ZnO-NPs hybrid 

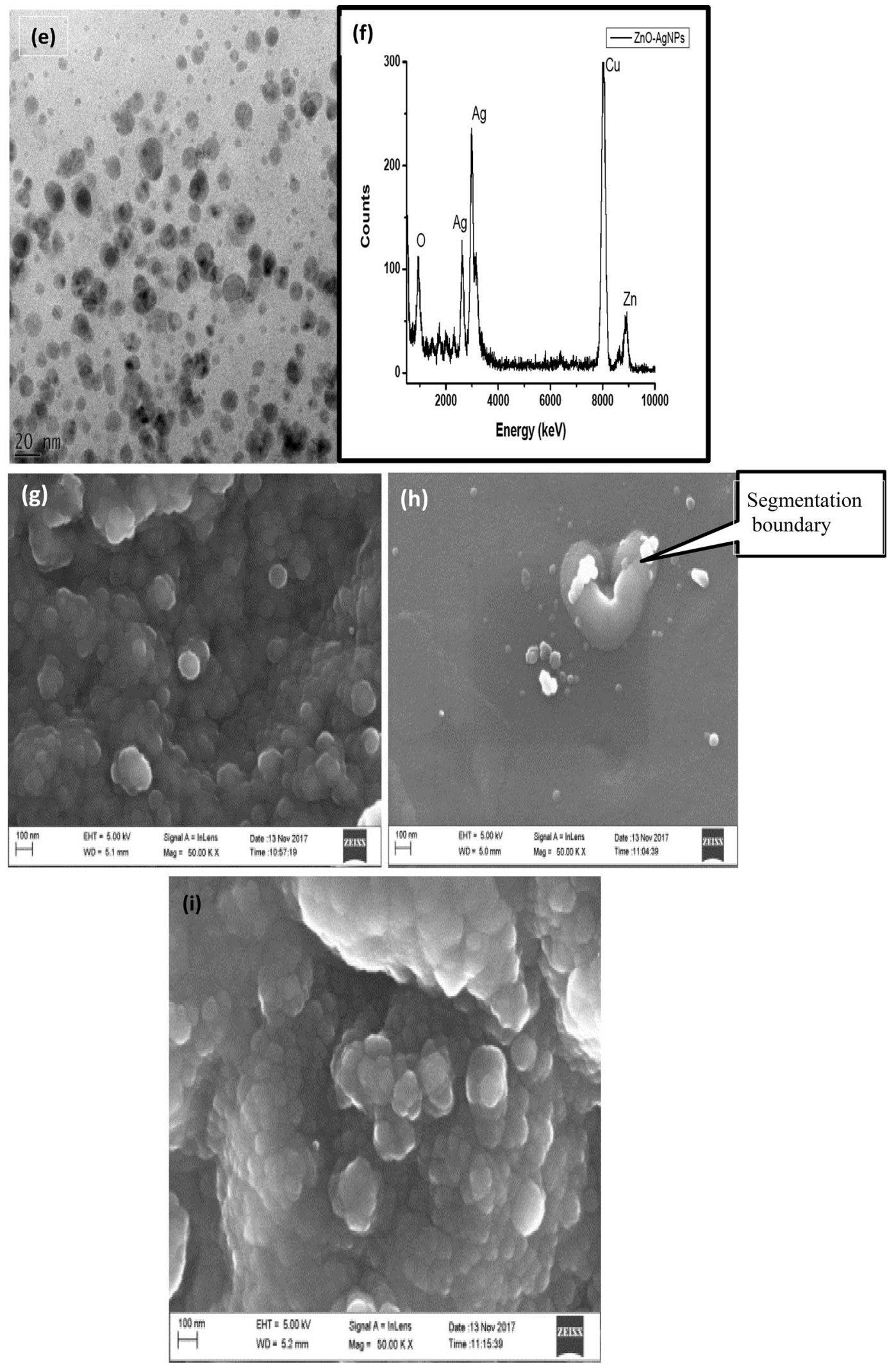

Fig. 6 (continued) 
probably because the sample was a $0.8-0.2$, Ag-NPs-ZnONPs respectively ratio.

\subsection{XRD results}

Three intense peaks at $2 \theta=38.05^{\circ}, 45.35^{\circ}$ and $64.42^{\circ}$ and can be indexed to the (111), (200) and (220) for the facecentered cubic silver as per the JCPDS card no. 89-3722 [80]. The fact that the XRD results displayed a high/signal to noise ratio could be instrumental but can also be due to the presence of crystalline biological materials from plant extract origin [81]. The Ag-NPs formed by the reduction of $\mathrm{Ag}^{+}$ions using Bidens pilosa leaf extract were crystalline in nature although the broad noisy base could be associated with the amorphous nature of the stabilizing/reducing agents. The intense peaks for ZnO-NPs occurring at $2 \theta=30.15^{\circ}, 35.74^{\circ}, 47.16^{\circ}$ and $56.67^{\circ}$ correspond to 100 , 101,102 and 110 planes of the Bragg's reflection of zinc. The peaks confirm $\mathrm{ZnO}$ hexagonal phase as compared to JCPDS card No. 89-7102 [82, 83]. The well resolved and sharp peaks show that the nanoparticles are crystalline in nature. XRD analysis showed distinct diffraction peaks at $2 \theta=38.05^{\circ}, 45.35^{\circ}$ and $64.42^{\circ}$ of (111), (200) and (220) for the face-centered cubic silver as per the JCPDS card no. $89-3722$ and $30.15^{\circ}, 35.74^{\circ}, 47.16^{\circ}$ and $56.67^{\circ}$ corresponding to $100,101,102$ and 110 for hexagonal $\mathrm{ZnO}-$ NPs as per JCPDS card No. 89-7102 respectively $[84,85]$. The peaks and the EDS elemental results which indicate the compositions of the various nanocomposites clearly indicate successful synthesis (Fig. 7).

\subsection{Antimicrobial activity of the nanohybrids}

In the testing of antimicrobial activity of the nanoparticles, two bacteria and one fungus were used. The Gram positive bacteria, S. aureus and the Gram negative bacteria E. coli were used as test microbes. The fungus, $C$. albicans was also used. For comparison purposes different nanoparticle ratios were used. In all the tests, clear halos indicating antimicrobial properties were evident. The strength of the antimicrobial activity depending on the nanoparticle composition ratio was fitted into zones of inhibition curves. Figures $8 \mathrm{a}-\mathrm{c}$ show optimal antimicrobial activity was attained at an Ag-NPs:ZnO-NPs ratio of 0.8:0.2
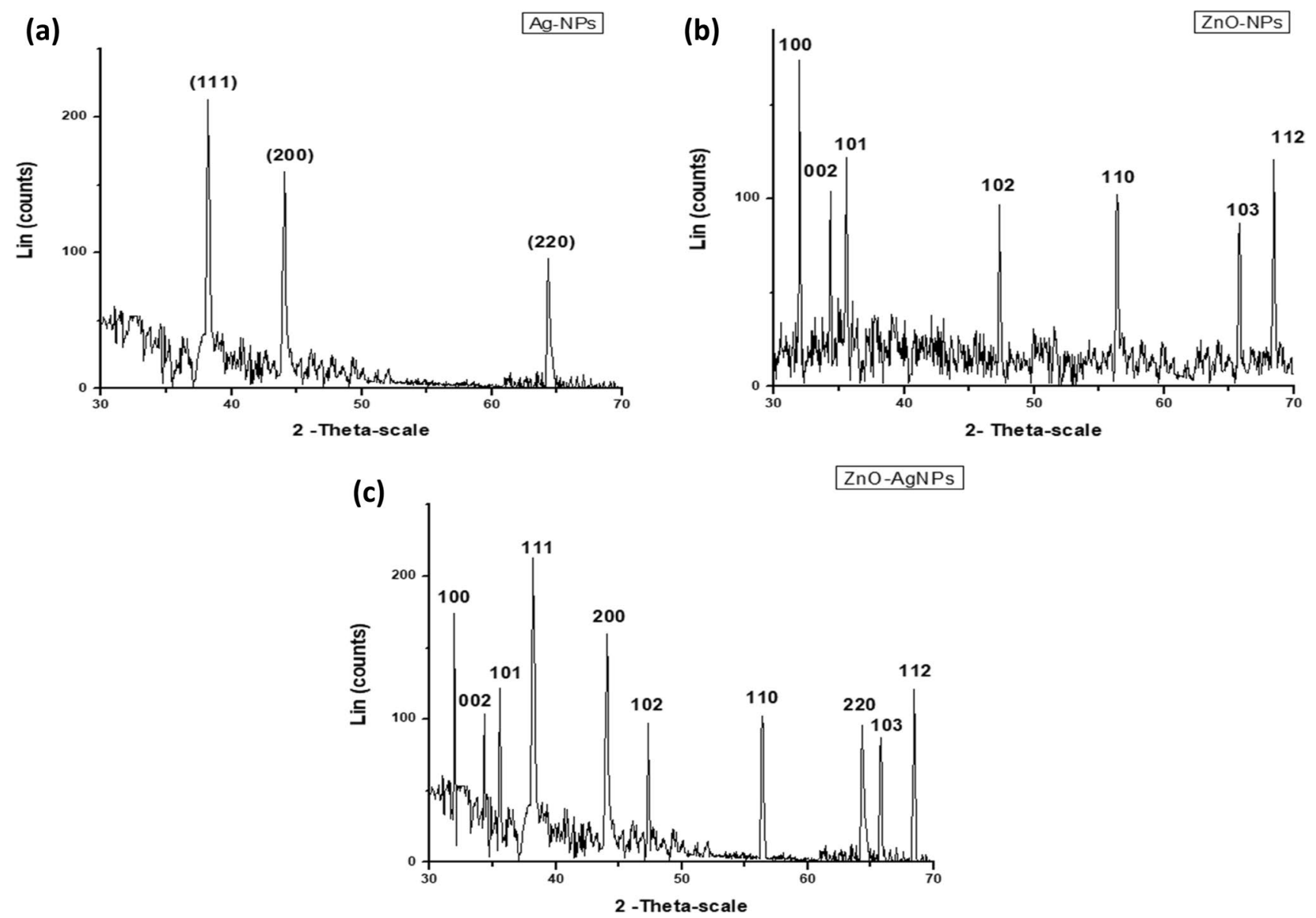

Fig. 7 a-c XRD results for Ag-NPs (a), ZnO-NPs (b) and Ag-NPs-ZnO-NPs (c) 

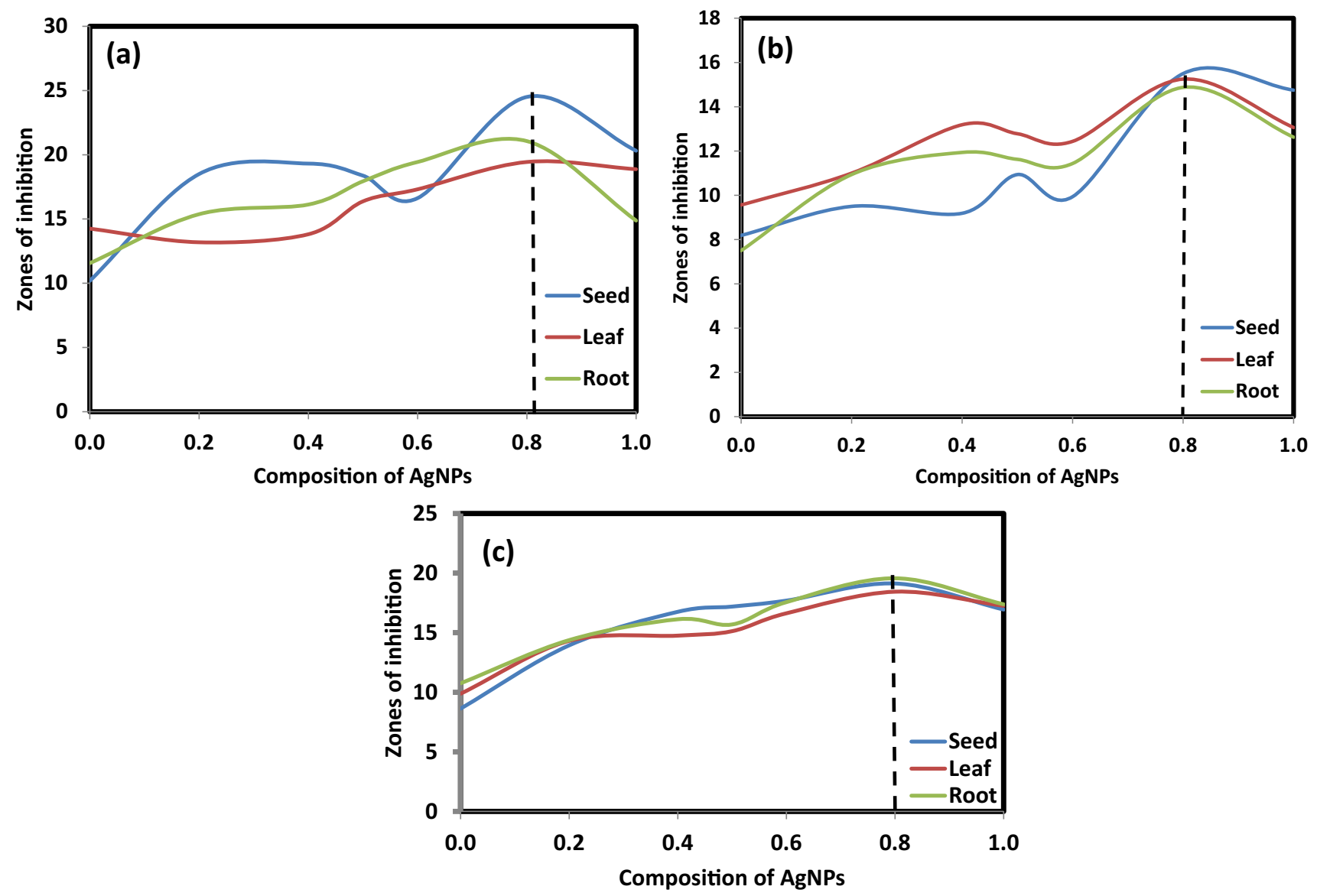

Fig. 8 a-c A graph of average values of zones of inhibition of (a) C. Albicans for nanoparticles obtained using seed, leaf and root extract against composition of silver nanoparticles b E. coli, c S. Aureus

nanoparticle composition translating into a $4: 1$ ratio. This result was so irrespective of the origin of the stabilizing reductants-leaf, root or seed as shown in Fig. 8a-c.

During this testing, chloramphenicol was used as positive control for E. coli and S. aureus. Fluconazole was the positive control for the fungus C. albicans. No inhibition zones were observed for $\mathrm{E}$. coli on the positive control (Chloramphenicol). This implies that the culture of E. coli that was used was resistant to the positive control. For the S. aureus, the positive control gave a zone of inhibition of $26.25 \pm 0.17 \mathrm{~mm}$. The positive control used for C. albicans, fluconazole gave an average zone of inhibition of $24.75 \pm 0.17 \mathrm{~mm}$ Fig. 9. Distilled water served as the negative control for all the micro-organisms since it was used to disperse the nanoparticles. No inhibition zones emanated from use of distilled water.

From the above results, the nanoparticles that exhibited highest antimicrobial activity were used to determine their minimum inhibition concentration (MIC). This is the lowest concentration of the nanoparticles that would inhibit the growth of the testing agents
namely-E. coli, S. aureus and C. albicans. The Ag-NPsZnO-NPs used were all in the optimal ratio of $0.8 \mathrm{Ag}-\mathrm{NPs}$ : $0.2 \mathrm{ZnO}-\mathrm{NPs}$ and prepared at an optimal temperature of $90^{\circ} \mathrm{C}$. Results were compared across the various plants parts source of stabilizing agents as follows; leaf extract originating nanoparticles denoted as (L90-0.8), seed extract originating nanoparticles denoted as (S 90-0.8) and root extract originating nanoparticles denoted as (R-90-0.8). The results for MIC are as shown in the Table 2.

According to the table, the seed originating nanoparticles (S90-0.8) and leaf originating nanoparticles (L900.8 ) exhibited a minimum inhibition concentration of $10 \mu \mathrm{g} / \mathrm{mL}$ for the $E$. coli and $1 \mu \mathrm{g} / \mathrm{mL}$ each for S. aureus and C. albicans. The nanoparticles of root origin, R90-0.8 showed an MIC of $1 \mu \mathrm{g} / \mathrm{mL}$ for all testing agents. Generally, this implied that, irrespective of the source, the nanoparticles were more effective on the $S$. aureus and C. albicans as compared to the $E$. coli. From the above results the $\mathrm{ZnO}-\mathrm{Ag}-\mathrm{NPs}$ of root origin were used to make a nanohybrid based antiseptic. 

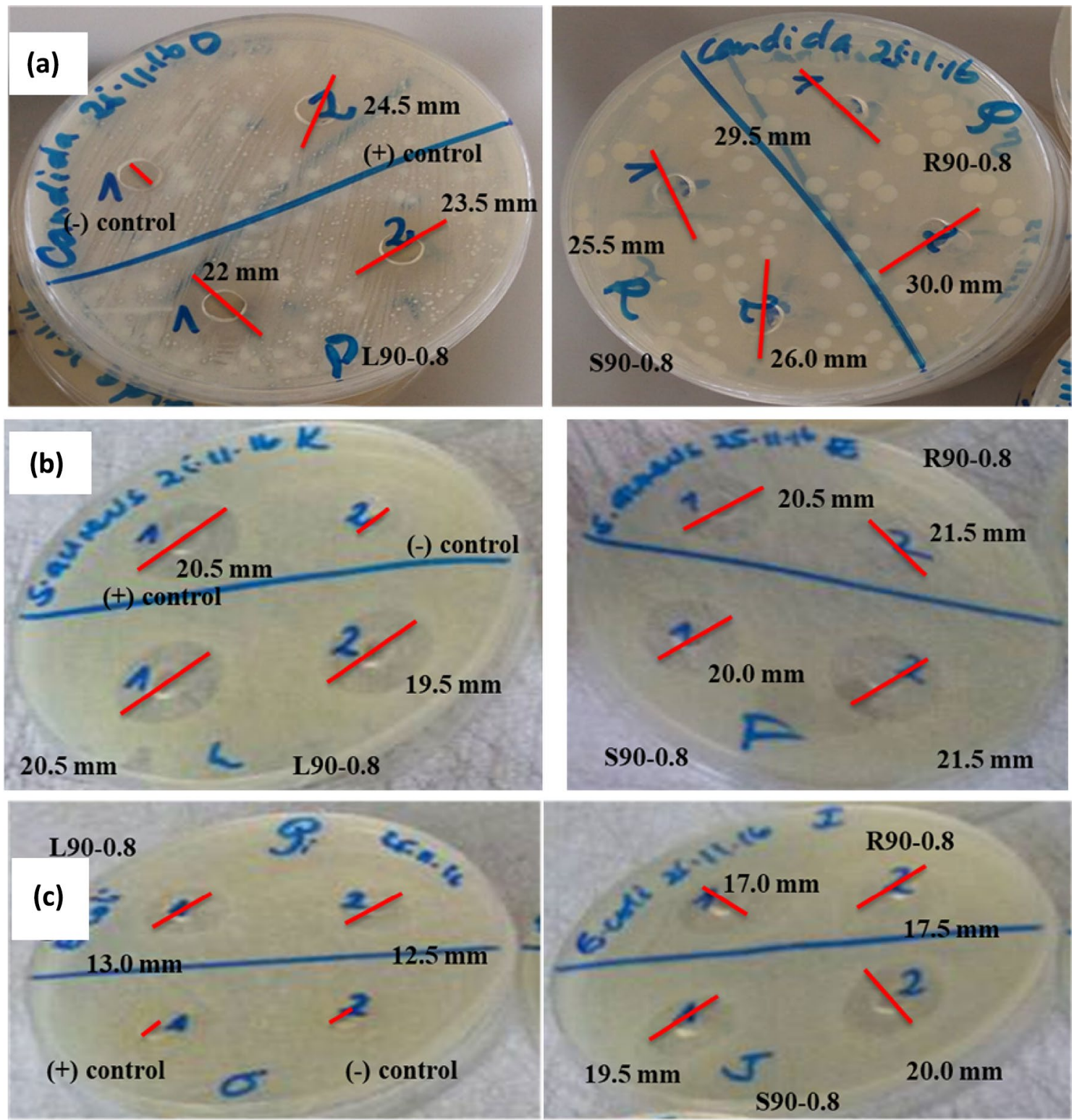

Fig. 9 Zones of inhibition for E. coli, S. aureus and C. albicans for the various nanoparticles

Table 2 Comparison of minimum inhibition concentration (MIC) for various nanoparticles

\begin{tabular}{|c|c|c|c|}
\hline \multirow[t]{2}{*}{ Microorganism } & \multicolumn{3}{|c|}{ MIC $(\mu \mathrm{g} / \mathrm{mL})$} \\
\hline & S90-0.8 & L90-0.8 & R90-0.8 \\
\hline E. coli & 10 & 10 & 1 \\
\hline S. aureus & 1 & 1 & 1 \\
\hline C. albicans & 1 & 1 & 1 \\
\hline
\end{tabular}

Table 3 The Ingredients of the formulated antiseptic (\% w/w)

\begin{tabular}{lcc}
\hline Component & Mass (g) & $\begin{array}{l}\text { Compo- } \\
\text { sition } \\
(\% \mathrm{w} / \mathrm{w})\end{array}$ \\
\hline Deionized water & 77.10 & 88.52 \\
Guar gum (gelling agent) & 0.70 & 0.80 \\
a-tocopherol (emollient) & 2.00 & 2.30 \\
ZnO-AgNPs (active ingredient) & 0.10 & 0.11 \\
Glycerin (humectant) & 7.00 & 8.04 \\
Fragrance & 0.20 & 0.23 \\
Total & 87.10 & 100.00 \\
\hline
\end{tabular}




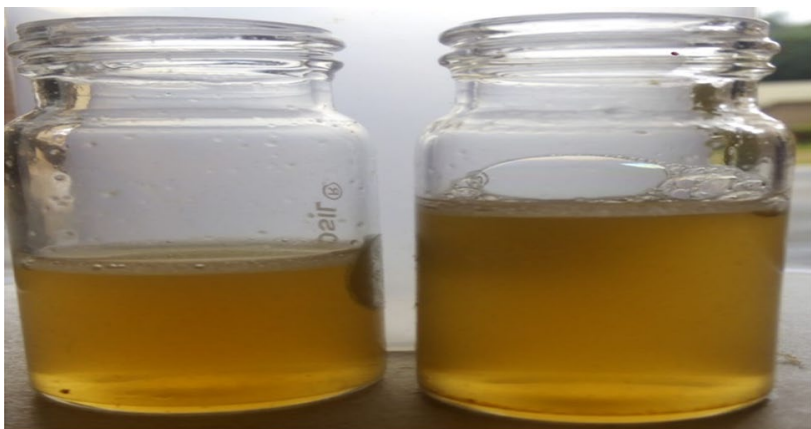

Fig. 10 Hand sanitizing antiseptic containing $\mathrm{ZnO}-\mathrm{Ag}-\mathrm{NPs}$ as active ingredient before shaking and after shaking

\subsection{Formulation of a nanohybrid based antiseptic}

Table 3 gives the $\%$ composition ( $\% \mathrm{w} / \mathrm{w}$ ) of the formulated antiseptic. \% composition of each component was worked out based on the formula;

$\%$ composition of component $=\frac{\text { Mass of component }}{\text { Mass of the antiseptic }}$

While as only the nanohybrids exhibited anti-microbial/ anti-fungal activity, other ingredients were added to improve the aesthetic nature of the yellowish foam forming antiseptic (Fig. 10).

\subsubsection{Antimicrobial activity of the formulated antiseptic}

In the testing of antimicrobial activity of the antiseptic, again the three test agents were used namely - the Gram positive $S$. aureus bacteria, the Gram negative $E$. coli bacteria, and the fungus $C$. albicans. In all the tests carried out, clear halos were observed as shown in Fig. 11, thus indicating inhibition of microbial growth by the antiseptic. The values of zones of inhibition were $14 \mathrm{~mm}$ for $E$. coli, $20.5 \mathrm{~mm}$ for S. aureus and $24.5 \mathrm{~mm}$ for $C$. albicans. These values for the zones of inhibition indicate that the hand sanitizer exhibited strong antimicrobial activity.

\section{Conclusion}

AgNPs, ZnONPs and $\mathrm{ZnO}-\mathrm{AgNPs}$ were synthesized using the seed, leaf and root extracts of Bidens pilosa. Although nanoparticle yield depended on temperature maximum yield attainment could not be associated to a particular plant extract source-root, leaf, seed. FT-IR and Raman spectra of the nanoparticles revealed the presence of functional groups $\mathrm{O}-\mathrm{H}, \mathrm{C}=\mathrm{C}, \mathrm{C}-\mathrm{H}$ aromatic, and $=\mathrm{C}-\mathrm{H}$

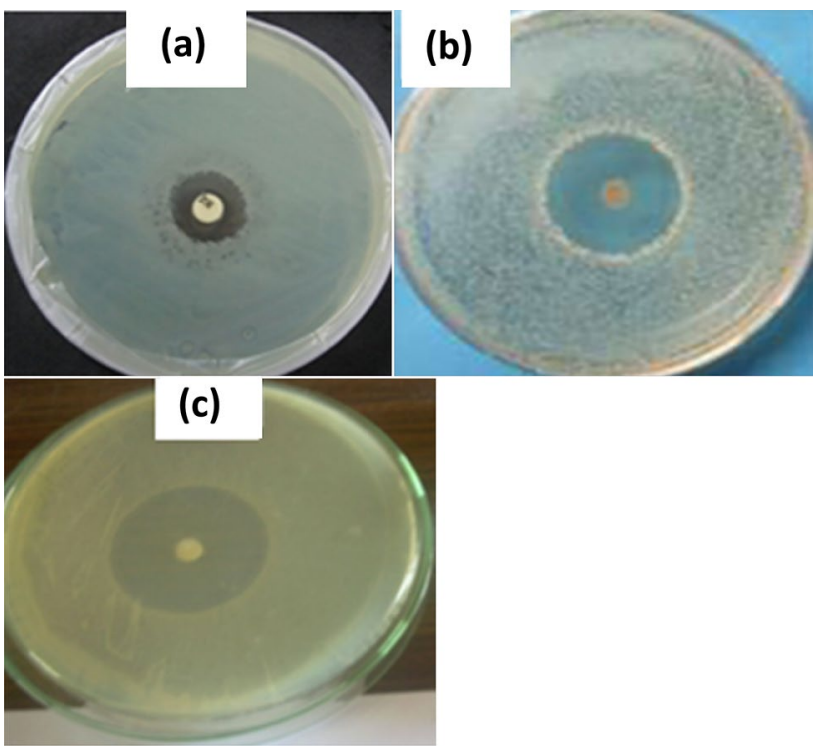

Fig. 11 Zones of inhibition for a E. coli, b S. aureus and c C. albicans for the hand sanitizing antiseptic formulated

which were responsible for reduction and stabilization of the nanoparticles. UV-Vis results for the for Ag-NPs displayed SPR bands at 408-411 $\mathrm{nm}$ but a red shift of the Ag-NPs band in the Ag-ZnO-NPs hybrid was associated with changes in the dielectric constant of the reaction media. The UV-visible results for the $\mathrm{ZnO}-\mathrm{NPs}$ observed at 365-372 $\mathrm{nm}$ shifted to high energy region for the Ag-ZnO-NPs probably indicating nanoparticle size reduction. The particles were found to have average mean size of 2-20 $\mathrm{nm}$ and were spherical in shape without significant agglomeration as revealed from the SEM and TEM analysis. EDX spectrum revealed the strong signal in the silver region confirming the presence of $\mathrm{Ag}$ and in the zinc region confirming the presence of $\mathrm{ZnO}$. The synthesized nanoparticles exhibited face-centered cubic crystals as demonstrated from XRD studies.

The results confirmed that in the medium treated with AgNPs, ZnONPs and ZnO-AgNPs, E. coli, S. aureus and C. albicans growth was inhibited. The ZnO-AgNPs with composition of $0.8 \mathrm{Ag} / 0.2 \mathrm{ZnO}$ gave the highest antimicrobial activity regardless of the extract used. From the $\mathrm{ZnO}-\mathrm{AgNPs}$ of the three extracts, those originating from the root extract showed the lowest Minimum Inhibition Concentration.

The root extract $\mathrm{ZnO}-\mathrm{AgNPs}$ (0.2:0.8) were used as active ingredients to formulate a hand sanitizing antiseptic. The antiseptic formed exhibited strong antimicrobial activity. Inhibition zones indicating antimicrobial activity of the hand antiseptic were $14 \mathrm{~mm} \mathrm{E}$. coli, $20.5 \mathrm{~mm}$ S. aureas and $24.5 \mathrm{~mm}$ C. albicans. 
Acknowledgements The study was conducted from University of Nairobi, Department of Chemistry, Department of Physics, Department of Biotechnology, and School of Microbiology and also at University of Western Cape, Sensor Lab-Department of Chemistry. It was funded by Deutscher Akademischer Austauschdienst (DAAD), REF: 57221138 and Kenya/South Africa collaborative grant REF: NCST/5/003/2/53, for the project titled, 'Nanobiosensor Chips for Anti-Tuberculosis'.

\section{Compliance with ethical standards}

Conflict of interest On behalf of all the authors, the corresponding author states that there is no conflict of interest.

\section{References}

1. World Health Organization (2015) Worldwide country situation analysis: response to antimicrobial resistance. http://apps. who.int/iris/bitstream/10665/163468/1/9789241564946_eng. pdf?ua=1\&ua=1, 15 May 2018

2. Tran QH, Nguyen VQ, Le AT (2013) Silver nanoparticles: synthesis, properties, toxicology, applications and perspectives. Adv Nat Sci Nanosci Nanotechnol 4(3):033001-033.18

3. Levy SB, Marshall B (2004) Antibacterial resistance worldwide: causes, challenges and responses. Nat Med 10(12s):S122-S129

4. Amábile-Cuevas CF, Cabrera R, Valenzuela F, Fuchs LY (1998) 11.3 antibiotic resistance and prescription practices in developing countries. In: Ketley J, Peter Williams GS (eds) Methods in microbiology, pp 587-594. http://www.sciencedirect.com/scien ce/article/pii/S0580951708703143, 7 Apr 2017

5. World Health Organization (2014) Antimicrobial resistance: global report on surveillance. https://www.who.int/drugresist ance/documents/surveillancereport/en/, 15 May 2018

6. Gelbrand H, Miller-Petrie M, Pant S, Gandra S, Levinson J, Barter D, Nga DT (2015) The State of the World's Antibiotics 2015. Wound Healing Southern Africa 8(2):30-34

7. Qiong Liu Ju, Li Xin Zhong, Dai Zan, Zhong Lu, Yang Hao, Chen Rong (2018) Enhanced antibacterial activity and mechanism studies of $\mathrm{Ag} / \mathrm{Bi} 2 \mathrm{O} 3$ nanocomposites. Adv Powder Technol 29(9):2082-2090

8. Lu Z, Rong K, Li J, Yang H, Chen R (2013) Size-dependent antibacterial activities of silver nanoparticles against oral anaerobic pathogenic bacteria. J Mater Sci Mater Med 24(6):1465-1471

9. Sharma VK, Yngard RA, Lin Y (2009) Silver nanoparticles: green synthesis and their antimicrobial activities. Adv Colloid Interface Sci 145(1-2):83-96

10. Le Ouay B, Stellacci F (2015) Antibacterial activity of silver nanoparticles: a surface science insight. Nano Today 10(3):339-354

11. Youssef AM, El-Nahrawy AM, Hammad ABA (2017) Sol-gel synthesis and characterizations of hybrid chitosan-PEG/calcium silicate nanocomposite modified with ZnO-NPs and (E102) for optical and antibacterial applications. Int J Biol Macromol 97:561-567

12. Grombone-Guaratini MT, Silva-Brandão KL, Solferini VN, Semir J, Trigo JR (2005) Sesquiterpene and polyacetylene profile of the Bidens pilosa complex (Asteraceae: Heliantheae) from Southeast of Brazil. Biochem Syst Ecol 33(5):479-486

13. Young PH, Hsu YJ, Yang WC (2010) Bidens pilosa L. and its medicinal use. In: Awaad AS, Singh VK, Govil JN (eds) Recent progress in medicinal plants, vol 28, 2nd edn. Stadium Press LLC, New Delhi, pp 411-426

14. Khoza BS, Gbashi S, Steenkamp PA, Njobeh PB, Madala NE (2016) Identification of hydroxylcinnamoyl tartaric acid esters in Bidens pilosa by UPLC-tandem mass spectrometry. South Afr J Bot 103:95-100

15. Bartolome AP, Villaseñor IM, Yang WC (2009) Bidens pilosa L. (Asteraceae): botanical properties, traditional uses, phytochemistry, and pharmacology. Evid Based Complement Altern Med 2013:1-51

16. Deba F, Xuan TD, Yasuda M, Tawata S (2008) Chemical composition and antioxidant, antibacterial and antifungal activities of the essential oils from Bidens pilosa Linn. var. Radiata. Food Control 19(4):346-352

17. Zulueta MCA, Tada M, Ragasa CY (1995) A diterpene from Bidens pilosa. Phytochemistry 38(6):1449-1450

18. Khan MR, Kihara M, Omoloso AD (2001) Antimicrobial activity of Bidens pilosa, Bischofia javanica, Elmerillia papuana and Sigesbekia orientalis. Fitoterapia 72:662-665

19. Chien SC, Young PH, Hsu YJ, Chen CH, Tien YJ, Shiu SY, Li TH, Yang CW, Marimuthu P, Tsai LFL, Yang WC (2009) Anti-diabetic properties of three common Bidens pilosa variants in Taiwan. Phytochemistry 70(10):1246-1254

20. Abd El-Gawad AM, Mashaly IA, Abu-Ziada ME, Deweeb MR (2015) Phytotoxicity of three Plantago species on germination and seedling growth of hairy beggarticks. Egypt J Basic Appl Sci 2(4):303-309

21. Chung CY, Yang WC, Liang CL, Liu HY, Lai SK, Chang CLT (2016) Cytopiloyne, a polyacetylenic glucoside from Bidens pilosa, acts as a novel anticandidal agent via regulation of macrophages. $J$ Ethnopharmacol 184:72-80

22. Yang HL, Chen SC, Chang NW, Chang JM, Lee ML, Tsai PC, Fu HH, Kao WW, Chiang HC, Wang HH, Hseu YC (2006) Protection from oxidative damage using Bidens pilosa extracts in normal human erythrocytes. Food Chem Toxicol 44(9):1513-1521

23. Liang D, Lu Z, Yang H, Gao J, Chen R (2016) A novel asymmetric wettable AgNPs/Chitosan wound dressing: in vitro and in vivo evaluation. ACS Appl Mater Interfaces 8(6):3958-3968

24. El-Nahrawy AM, Ali Al, Hammad ABA, Youssef AM (2016) Influences of Ag-NPs doping chitosan/calcium silicate nanocomposites for optical and antibacterial activity. Int J Biol Macromol 93:267-275

25. Vaseem M, Umar A, Han YB (2010) Metal oxide nanostructures and their applications. Am Sci Publ 5:479-509

26. Kim JS, Kuk E, Yu KN, Kim JH, Park SJ, Lee HJ et al (2007) Antimicrobial effects of silver nanoparticles. Nanomed Nanotechnol Biol Med 3(1):95-101

27. Sondi I, Salopek-Sondi B (2004) Silver nanoparticles as antimicrobial agent: a case study on E. coli as a model for Gram-negative bacteria. J Colloid Interface Sci 275(1):177-182

28. Huh AJ, Kwon YJ (2011) “Nanoantibiotics”: a new paradigm for treating infectious diseases using nanomaterials in the antibiotics resistant era. J Control Release 156(2):128-145

29. Gunalan S, Rajeswari S, Venckatesh R (2012) Green synthesized zinc oxide nanoparticles against bacterial and fungal pathogens. Prog Nat Sci Mater Int 22(6):693-700

30. Feris K, Otto C, Tinker J (2010) Electrostatic Interactions affect nanoparticle-mediated toxicity to Gram (-) bacterium, Pseudomonas aeruginosa. Langmuir 26(6):4429-4436

31. Gupta J, Mohapatra J, Bahadur D (2017) Visible light driven mesaporous Ag-embedded $\mathrm{ZnO}$ nanocomposites: reactive oxygen species enhanced photocatalysis, bacterial inhibition and photodynamic therapy. Dalton Trans 46:685-696

32. Liu Q, Liu E, Li J, Qiu Y, Chen R (2019) Rapid ultrasonic-microwave assisted synthesis of spindle-like $\mathrm{Ag} / \mathrm{ZnO}$ nanostructures and their enhanced visible-light photocatalytic and antibacterial activities. Catal Today. https://doi.org/10.1016/j.catto d.2019.01.017

33. Lu Z, Gao J, He Q, Wu J, Liang D, Yang H, Chen R (2017) Enhanced antibacterial and wound healing activities of microporous 
chitosan-Ag/ZnO composite dressing. Carbohyd Polym 156:460-469

34. Oliveira F, Andrade-Neto V, Krettli A, Brandão MG (2004) New evidences of antimalarial activity of Bidens pilosa roots extract correlated with polyacetylene and flavonoids. J Ethnopharmacol 93(1):39-42

35. Brandao MGL, Nery CGC, Mamao MAS, Krettli AU (1998) Two methoxylated flavone glycosides from Bidens pilosa. Phytochemistry 48(2):397-399

36. Adedapo A, Jimoh F, Afolayan A (2011) Comparison of the nutritive value and biological activities of the acetone, methanol and water extracts of the leaves of Bidens pilosa and Chenopodium album. Acta Pol Pharm 68(1):83-92

37. Cortés-Rojas DF, Chagas-Paula DA, Da Costa FB, Souza CRF, Oliveira WP (2013) Bioactive compounds in Bidens pilosa L. populations: a key step in the standardization of phytopharmaceutical preparations. Rev Bras Farmacogn 23(1):28-35

38. Chauhan I, Aggrawal S, Mohanty P (2015) Metal oxide nanostructures incorporated/immobilized paper matrices and their applications: a review. RSC Adv 5(101):83036-83055

39. Padalia H, Chanda S (2017) Characterization, antifungal and cytotoxic evaluation of green synthesized zinc oxide nanoparticles using Ziziphus nummularia leaf. Artif Cells Nanomed Biotechnol 45(8):1751-1761

40. Sharma VK, Yngard RA, Lin Y (2008) Silver nanoparticles: green synthesis and their antimicrobial activities. Adv Colloid Interface Sci 145(1-2):83-96

41. Ju-Nam Y, Lead JR (2008) Manufactured nanoparticles: an overview of their chemistry, interctions and potential environmental implications. Sci Total Environ 400:396-414

42. Okeke IN, Sosa A (2003) Antibiotic resistance in africa-discerning the enemy and plotting a defence. Afr Health 25(3):10-15

43. De M, Ghosh PS, Rotello VM (2008) Applications of nanoparticles in biology. Adv Mater 20(22):4225-4241

44. Lu H, Salabas EL, Schuth F (2007) Magnetic nanoparticles: synthesis, protection, functionalization and application. Angew Chem Int Ed Eng 46(8):1222-1244

45. Chaudhhuri RG, Paria S (2012) Core/shell nanoparticles: classes, properties, synthesis mechanisms, characterization, and applications. Am Chem Soc 112(4):2373-2433

46. Singhal G, Bhavesh R, Kasariya K, Sharma A, Singh RP (2011) Biosynthesis of silver nanoparticles using Octinum sanctum (Tulsi) leaf extract and screening its antimicrobial activity. J Nanopart Res 13:2981-2988

47. Krutyakov YA, Kudrinskiy AA, Olenin AY, Lisichkin GV (2008) Synthesis and properties of silver nanoparticles: advances and prospects. Russ Chem Rev 77(3):233-257

48. Youssef AM, Abdel-Aziz MS, El-Sayed SM (2014) Chitosan nanocomposite films based on Ag-NP and Au-NP biosynthesis by Bacillus subtilis as packaging materials. Int J Biol Macromol 69:185-191

49. Ahamed M, Alsalhi MS, Siddiqui MK (2010) Silver nanoparticle applications and human health. Clin Chim Acta 411:1841-1848

50. Varghese E, George M (2015) Green synthesis of zinc oxide nanoparticles. Int J Adv Res Sci 4(1):307-314

51. Patil RS, Kokate MR, Kolekar SS (2012) Bioinspired synthesis of highly stabilized silver nanoparticles using Ocimum tenuiflorum leaf extract and their antibacterial activity. Spectrochim Acta A Mol Biomol Spectrosc 91:234-238

52. Chen SF, Zhang H (2012) Aggregation kinetics of nanosilver in different water condition. Adv Nat Sci Nanosci Nanotechnol 3:035006-11-035006-7

53. Dang TMD, Le TTT, Blance EFM, Dang C (2012) Influence of surfactant on the preparation of silver nanoparticles by polyol method. Adv Nat Sci Nanosci Nanotechnol 3:035004-1-035004-4
54. Sun Y, Xia Y (2002) Shape-controlled synthesis of gold and silver nanoparticles. Science 298:2176-2179

55. Shah RK, Boruah F, Parween N (2015) Synthesis and characterization of $\mathrm{ZnO}$ nanoparticles using leaf extract of Camellia sinesis and evaluation of their antimicrobial efficacy. Int J Curr Microbiol Appl Sci 4(8):444-450

56. Devi RS, Gayathri R (2014) Green Synthesis of zinc oxide nanoparticles by using Hibiscus rosa-sinensis. Int J Curr Eng Technol 4:2444-2446

57. Rodríguez-León E, Iñiguez-Palomares R, Navarro RE, Herrera-Urbina $R$, Tánori J, Iñiguez-Palomares C, Maldonado A (2013) Synthesis of silver nanoparticles using reducing agents obtained from natural sources (Rumex hymenosepalus extracts). Nanoscale Res Lett 8(1):318

58. Alagummuthu G, Kirubha R (2012) Green synthesis of silver nanoparticles using Cissus quadrangularis plant extract and their antibacterial activity. Int J Nanomater Biostruct 2(3):30-33

59. Awwad AM, Albiss B, Ahmad AL (2014) Green synthesis, characterization and optical properties of zinc oxide nanosheets using Olea europea leaf extract. Adv Mater Lett 5(9):520-524

60. Raut S, Thorat PV, Thakre R (2013) Green synthesis of zinc oxide $(\mathrm{ZnO})$ nanoparticles using Ocimum tenuiflorum leaves. IJSR 4(5):1225-1226

61. Mason C, Vivekanandha S, Misra M, Mohanty AK (2012) Switch grass (Panicum virgatum) extract medicated green synthesis of silver nanoparticles. World J Nanosci Eng 12:47-52

62. Yu Y, Yang W, Sun X, Zhu W, Li XZ, Sellmyer DJ, Sun S (2014) Monodisperse MPt ( $\mathrm{M}=\mathrm{Fe} \mathrm{Co}, \mathrm{Ni}, \mathrm{Cu}, \mathrm{Zn}$ ) nanoparticles prepared from a facile oleylamine reduction of metal salts. Nano Lett 14(5):2778-2782

63. Tien DC, Tseng KH, Liao CY, Huang JC, Tsung TT (2008) Discovery of ionic silver in silver nanoparticle suspension fabricated by arc discharge method. Alloys Compd 463:408-411

64. Sintubin L, Verstrate W, Boon N (2012) Biologically produced nanosilver: current state and future perspectives. Biotechnol Bioeng 10(9):2422-2436

65. Mishra V, Sharma R (2015) Green synthesis of zinc oxide nanoparticles using fresh peels extract of punica granatum and its antimicrobial activities. IJPRUR 3:694-699

66. Bhainsa KC, Souza S (2006) Extracellular biosynthesis of silver nanoparticles using fungus Aspergillus fumigates. Colloids Surf B Biosurf 47:160-164

67. Desai R, Mankad V, Gupta S, Jha P (2012) Size distribution of silver nanoparticles: UV-visible spectroscopic assessment. Nanosci Nanotechnol Lett 4(1):30-34

68. Saion E, Gharibshahi E, Naghavi K (2013) Size-controlled and optical properties of monodispersed silver nanoparticles synthesized by the radiolytic reduction method. Int J Mol Sci 14(4):7880-7896

69. Raza S, Yan W, Stenger N, Wubs M, Mortensen NA (2013) Blueshift of the surface plasmon resonance in silver nanoparticles: substrate effects. Opt Express 21(22):27344

70. Tao A, Sinsermsuksakul P, Yang P (2007) Tunable plasmonic lattices of silver nanocrystals. Nat Nanotechnol 2(7):435

71. Chen CF, Tzeng SD, Chen HY, Lin KJ, Gwo S (2008) Tunable plasmonic response from alkanethiolate-stabilized gold nanoparticle superlattices: evidence of near-field coupling. J Am Chem Soc 130(3):824-826

72. Liz-Marzán LM (2006) Tailoring surface plasmons through the morphology and assembly of metal nanoparticles. Langmuir 22(1):32-41

73. Jung YS, Wuenschell J, Kuokim H, Kaur P, Waldeck DH (2009) Blue shift of surface plasmon resonance in a metalnanoslit array structure. Opt Express 17(18):16081-16090 
74. Mankad V, Kumar RK, Jha P (2013) Investigation of blue-shifted plasmon resonance: an optical properties study of silver nanoparticles. Nanosci Nanotechnol Lett 5(8):889-894

75. Dai J, Mumper RJ (2010) Plant phenolics: extraction, analysis and their antioxidant and anticamcer properties. Molecules 15(10):7313-7352

76. Vivek RT, Muthuchelian R, Gunasekaran K, Kaveri P, Kannan K (2012) Green biosynthesis of silver nanoparticles from Annona squamosa leaf extract and its in vitro cytotoxic effect on MCF-7 cells. AGRIS 47(12):2405-2410

77. Santhoshkumar J, Kumar SV, Rajeshkumar S (2017) Synthesis of zinc oxide nanoparticles using plant leaf extract against urinary tract infection pathogen. Resour Effic Technol 3(4):459-465

78. Chen M, Feng YM, Wang X, Li TC, Zhang JY, Qian DJ (2007) Silver nanoparticles capped by oleylamine: formation, growth, and self-organization. Langmuir 23(10):5296-5304

79. Elumalai K, Velmurugan S (2015) Green synthesis, characterization and antimicrobial activities of zinc oxide nanoparticles from the leaf extract of Azadirachta indica (L.). Appl Surf Sci 345:329-336

80. Ferni V, Prabha PH, Sudha P, Devibala B, Jerald A (2011) Antibacterial effect of $\mathrm{ZnO}-\mathrm{Au}$ nanocomposites. Int J Biotechnol 1:1-8
81. Forough M, Farhadi K (2010) Biological and green synthesis of silver nanoparticles. Turk J Eng Environ Sci 34(4):281-287

82. Ruparelia JP, Chatterjee AK, Duttagupta SP, Mukherji S (2008) Strain specificity in antimicrobial activity of silver and copper nanoparticles. Acta Biomater 4(3):707-716

83. Sondi I, Salopek-Sondi B (2004) Silver nanoparticles as antimicrobila agent: a case study on E. coli as a model for Gram-negative bacteria. J Colloid Interface Sci 275:177-182

84. Ibrahim HMM (2015) Green synthesis and characterization of silver nanoparticles using banana peel extract and their antimicrobial activity against representative microorganisms. J Radiat Res Appl Sci 8(3):265-275

85. Okafor F, Janen A, Kukhtareva T, Edwards V, Curley M (2013) Green synthesis of silver nanoparticles, their characterization, application and antibacterial activity. Int J Environ Res Public Health 10(10):5221-5238

Publisher's Note Springer Nature remains neutral with regard to jurisdictional claims in published maps and institutional affiliations. 